\title{
Diet and behavioral habits related to oral health in eating disorder patients: $a$ matched case-control study
}

\author{
Ann-Katrin Johansson ${ }^{1 *} \mathbb{D}$, Claes Norring ${ }^{2}$, Lennart Unell ${ }^{3}$ and Anders Johansson ${ }^{4}$
}

\begin{abstract}
Background: Patients suffering from eating disorders (ED) have a substantially increased risk for developing poor oral health. In this regard, dietary habits in combination with obsessive behavior as well as the expression and intensity of the disease are of utmost importance. This study aimed to investigate diet and behavioral habits in patients with ED compared to healthy controls.
\end{abstract}

Methods: All patients who initiated treatment in an ED clinic during 1 year were invited to participate in the study. Sixty-five patients were admitted out of which 54 agreed to participate: 50 women and 4 men, mean age 21.5 years, range 10-50 years. From a public dental health clinic, 54 sex-and age-matched controls where selected. In all participants a comprehensive questionnaire was completed. ED patients were analyzed with respect to their selfperceived disease state: when they felt "relatively good" (ED-good) and "bad" (ED-bad) as well as if they reported vomiting or not.

Results: The ED-good patients reported significantly higher intake of caffeine-containing and cola light soft drinks and both study groups reported a lower intake of regularly sweetened carbonated drinks compared to controls. ED-bad reported significantly lower intake of number of meal and sweet intake while both study groups brushed their teeth more frequently than controls. As regards awareness of detrimental dietary intake and the possible risk for oral health complications did not differ between patients and controls except that the ED groups were more aware that vomiting and brushing thereafter could damage their teeth. ED patients went less often to the dentist for regular checkups than controls. Vomiting ED patients differed in several of the parameters related to dietary and other behaviors compared to no vomiting subjects. According to regression analyses and compared to healthy controls, predictive variables for ED-good were: higher intake of caffeine containing drinks (OR 1.34, Cl 1.10-1.64) and lower intake of regular soft drinks (OR 0.57, Cl 0.35-0.94). For ED-bad, lower frequency intake of lunch meals (OR 0.59, Cl 0.39-0.88) and sweet biscuits were predictive (OR 0.15, Cl 0.05-0.48).

Conclusions: ED patients present a number of dietary and other types of behavior that are potentially harmful for oral health. It is important to retrieve reports on the ED behaviors in both relatively good and bad disease state in order for the medical team to prescribe adequate advice and treatment.

Keywords: Awareness, Behaviors, Diet, Oral hygiene, Risk factors, Soft drinks

\footnotetext{
* Correspondence: Ann-Katrin.Johansson@uib.no

${ }^{1}$ Department of Clinical Dentistry-Cariology, Faculty of Medicine, University of

Bergen, Årstadveien 19, 5009 Bergen, Norway

Full list of author information is available at the end of the article
}

(c) The Author(s). 2020 Open Access This article is distributed under the terms of the Creative Commons Attribution 4.0 International License (http://creativecommons.org/licenses/by/4.0/), which permits unrestricted use, distribution, and reproduction in any medium, provided you give appropriate credit to the original author(s) and the source, provide a link to the Creative Commons license, and indicate if changes were made. The Creative Commons Public Domain Dedication waiver (http://creativecommons.org/publicdomain/zero/1.0/) applies to the data made available in this article, unless otherwise stated. 


\section{Plain English summary}

Patients suffering from eating disorders have an increased risk for developing poor oral health. In this regard, the fluctuating severity of the disease may be connected to changes in behavior pattern such as more unhealthy way of eating and drinking as well as in harmful oral hygiene habits. This study examined diet and behavioral habits in patients with eating disorders when they felt relatively good or bad in their disease compared to healthy controls.

Depending on the self-perceived disease condition (relatively good or bad), eating disorders patients consume more caffeine-containing and cola light soft drinks, lesser sweet carbonated drinks and number of meals. They also brushed their teeth more frequently but went less often for dental check-up than controls. Predictive factors for being an eating disorder patents were higher intake of caffeine containing drinks, lower intake of sweet soft drinks and biscuits and reduced number of lunch meals. Eating disorder patients present a number of dietary and other types of behavior that are potentially harmful for oral health. It is important to retrieve reports on behaviors in both relatively good and bad disease state in order for the medical team to prescribe adequate advice and treatment.

\section{Introduction}

Patients suffering from eating disorders (ED) such as Anorexia Nervosa (AN), Bulimia Nervosa (BN) and eating disorders otherwise not specified (EDNOS) have a substantially increased risk for developing poor oral health. In this regard, the combination of harmful dietary habits, self-induced vomiting, impaired salivary conditions and less favorable oral hygiene habits will increase the risk for oral diseases such as dental erosion and dental caries( [1]) as well as for temporomandibular disorder (TMD) [2]. In a meta-analysis comprising ten studies, the odds for presenting hyposalivation and dental erosion was about 2-7 times higher in ED patients compared to controls. Dental caries, based on decayedmissing-filled surfaces (DMFS), was in average 3.07 lower in controls compared to those diagnosed with ED [3]. ED are difficult to treat and although many individuals recover in the long term, a prolonged course with recurring relapses and an elevated risk of premature death is not unusual $[4,5]$.

Dietary habits in combination with obsessive behavior as well as the expression and intensity of the disease are of utmost importance for oral health in ED patients [6]. This connection is especially apparent between bulimic behaviors and dental erosion. The acidic challenge for the teeth in bulimic patients is depending not only on the type of the diet or drinks ingested but also in purging behavior caused by the gastric hydrochloric acid reaching the oral cavity [7-9]. Consumption of regularly sweetened soft drinks and juices will increase the risk for both dental erosion and caries, and artificially sweetened soft drinks, without regular sugar, will increase the risk for dental erosion [10]. In this regard, it has been found that patients with ED use soft drinks with artificial sweeteners more often than controls [11] and it has been suggested that they choose to drink diet drinks in order to control both their appetite and weight. It has even been suggested that monitoring intake of low-calorie diet in ED patients, such as light soft drinks, may be of importance when predicting the treatment outcome of an ED $[12,13]$. Besides the choice of dietary products, the pattern of consumption, oral hygiene habits and awareness about possible negative factors for oral health as well as utilization of dental care services are other behaviors that may be of importance. The effect of these behaviors may also be influenced by the common variation in ED symptomatology, with the patient having alternate periods of bad or relatively healthy/good disease state.

The aim of this study is to investigate the abovementioned behaviors in ED patients during periods when their self-perceived ED status was "relatively good" vs. "bad", compared to sex- and age-matched healthy controls. The hypothesis of this study is that diet and other behavioral habits differs among ED patients depending on their disease state.

\section{Materials and methods}

\section{Participant selection}

Sixty-five consecutive patients attending the Eating Disorder Clinic, Örebro County Council, Örebro, Sweden during one-year period were invited to participate in the study. Fifty-four of those accepted and a sex and age matched control group was selected from a Public Dental Health Clinic, Örebro, Sweden. All controls were tested for possible ED diagnosis using the Symptom Index of the Eating Disorder Inventory-2 (EDI-2) [14]. Two controls had a risk for ED diagnosis and were offered a referral to a specialized ED clinic. Two new controls were selected and both of them scored negatively for ED by the EDI-2. Detailed information of the selection of participants has been reported elsewhere [1].

\section{Questionnaire}

A questionnaire was created together with the medical personnel working at the ED clinic (Additional file 1). It was tested on a group of five subjects and thereafter reassessed and changed according to the comments from the test persons. The questionnaire finally comprised 196 questions on sociodemographic factors, general and oral health including dietary and oral hygiene habits as well as aspects related to utilization of dental care. It was given to both the ED group and controls 
except for some questions that were specifically designed for the ED-patients and therefore not relevant for the controls. The ED group was asked to respond to the questions based on their self-perceived ED status, i.e. when they judged their ED condition as "relatively good" (ED-good) or as "bad" (ED-bad). Consequently, all ED patients $(n=54)$ answered the two questions. The same question was always given twice, where the patients had to assess the severity of their ED when they were feeling "relatively good" and "bad". Example of questions: When you feel (relatively good/bad) in your eating disorder, what do you drink/eat (certain items)? When you feel (relatively good/bad) in your eating disorder, how often do you eat breakfast, lunch, dinner and snacks in between meals? In a similar way, dietary questions were given that included type and amount of drink intake, fruit consumption and intake of sweets, biscuits, hard cheese, milk, yoghurt/sour milk and number of meals. Questions about the participants' awareness of the possible danger for oral health problems from consuming certain food and drink items were also given for the "relatively good" and "bad" ED states. So were questions about oral hygiene habits, e.g. brushing frequency, proximal cleaning, and usage of tooth paste. Utilization of dental care comprised questions on regular recall frequency, emergency visits, confidence in dental care system and dental fear. Detailed methodology in recordings of oral health status, TMD problems and salivary factors have previously been reported on $[1,2,15]$.

\section{Statistical methods}

Statistical Package for the Social Sciences (SPSS version 24.0, IBM SPSS Corp., Armonk, NY, USA). Differences between ED patients (in relatively good and bad state) and controls were calculated with Friedmans test and differences within the three groups with the Wilcoxon Signed Ranks Test as Post Hoc test. Bonferroni correction was applied and a $p$-value of $\leq 0.017$ was therefore considered significant in case of three pairwise comparisons. In addition to comparing the broad ED group with its matched control, McNemar's test was used for dichotomous data and Wilcoxon signed Rank test for numerical and ordered ordinal data. In addition, the ED patients were divided on those who reported vomiting and those who did not and their responses to the questionnaire were analyzed in the same manner as for EDgood/bad described above.

Variables related to dietary habits between ED (in relatively good and bad state) and controls were analyzed by conditional logistic regression using the nomreg and the Cox procedures. For each of the regression analyses, six independent variables were selected among those found significantly different in bivariate comparisons without consideration to the Bonferroni correction.

\section{Results}

The mean age for both patients and controls was 21.5 years ( $\mathrm{SD}=6.8$, range $10-50 ; 100$ females, 8 males). Regarding ED diagnoses $28 \%$ of the patients presented with anorexia nervosa (AN, 14/54), 14\% with bulimia nervosa (BN, 8/54) and 58\% with eating disorder not otherwise specified (EDNOS, 32/54). The diagnoses were given according to DSM-IV [16]. The mean age at the onset and duration of ED in the study group was 16 years (range 9-26) and 4.5 years (range $0.3-35$ ), respectively.

Vomiting was reported by $25 \mathrm{ED}$ patients and no vomiting by 29 patients. The distribution of ED diagnoses in the vomiting group was, 17 EDNOS, $7 \mathrm{BN}$ and 1 $\mathrm{AN}$. The corresponding figures for the no vomiting group was 15 EDNOS, $13 \mathrm{AN}, 1 \mathrm{BN}$.

\section{Diet}

The questionnaire gave report on different types of drinks and foods consumed in the ED group during selfassessed severity of the disease, i.e. relatively good and bad disease state, both of which was compared to that of responses from healthy controls.

\section{Drink consumption}

The total intake of soft drinks during relatively good and bad conditions of ED compared to controls is presented in Table 1. Friedman test for multiple comparisons between the three groups showed significant differences in reported intake of cola, other regular (sweetened) carbonated soft drinks, nutrition drinks and milk. Pairwise comparisons between ED-good and matched control applying Bonferroni correction showed that yearly consumption of Cola light was significantly higher in the ED-good group compared to controls $(41.4 \mathrm{~L}$ vs. $6.6 \mathrm{~L}$; $p=0.014)$ and the same applied about nutrition drinks (25.3 L vs. $0 \mathrm{~L} ; p=0.003)$. The controls had a significantly higher yearly intake than both ED-good and EDbad as regard Cola regular $(22.6 \mathrm{~L}$ vs. $8.7 \mathrm{~L}$ vs. $12.3 \mathrm{~L}$; $p=0.001$ and $p=0.005)$ and other carbonated regular soft drinks $(20.7 \mathrm{~L}$ vs. $5.3 \mathrm{~L}$ vs. $8.0 \mathrm{~L} ; p=0.003$ and $p=$ 0.010). Milk consumption was significantly higher in controls (107 L/year) compared to ED-bad (69.5 L/year) $(p=0.004)$.

Descriptive data and inferential analyzes for the vomiting and no vomiting groups are described in the Additional file 2: Tables S1 and S2. Vomiting ED patients reported significantly higher intake of Cola light in ED-good $(79.9 \mathrm{~L})$ compared to matched controls $(6.8 \mathrm{~L})$ $(p=0.003)$. No differences as regard Cola light consumption were found in the no vomiting group. In the no vomiting group, Cola regular consumption was significantly higher in the controls $(27.3 \mathrm{~L})$ compared to both ED-good $(11.0 \mathrm{~L})$ and bad $(10.8 \mathrm{~L})(p=0.004$ and $p=0.005$, respectively. No differences in Cola regular intake were found the 
Table 1 Total Drink Intake (L/yr) in Relatively Good and Bad Disease State Compared to Healthy Controls

\begin{tabular}{|c|c|c|c|c|c|c|c|c|c|c|}
\hline & \multicolumn{2}{|c|}{$\begin{array}{l}\text { Relatively good } \\
(n=54)\end{array}$} & \multicolumn{2}{|l|}{$\begin{array}{l}\text { Bad } \\
(n=54)\end{array}$} & \multicolumn{2}{|l|}{$\begin{array}{l}\text { Control } \\
(n=54)\end{array}$} & \multirow[b]{2}{*}{$P$} & \multirow[b]{2}{*}{$P_{1}$} & \multirow[b]{2}{*}{$P_{2}$} & \multirow[b]{2}{*}{$P_{3}$} \\
\hline & Mean \pm SD & Range & Mean \pm SD & Range & Mean \pm SD & Range & & & & \\
\hline Cola light & $41.4 \pm 108.0$ & $0-566$ & $63.1 \pm 198.7$ & $0-1205$ & $6.6 \pm 16.6$ & $0-85$ & 0.019 & 0.014 & NS & NS \\
\hline Cola regular & $8.7 \pm 42.4$ & $0-301$ & $12.3 \pm 48.8$ & $0-301$ & $22.6 \pm 34.4$ & $0-151$ & 0.0001 & 0.001 & 0.005 & NS \\
\hline Other carbonated light soft drinks & $13.6 \pm 75.2$ & $0-547$ & $19.9 \pm 89.3$ & $0-548$ & $11.7 \pm 37.1$ & $0-183$ & NS & NS & NS & NS \\
\hline Other carbonated regular soft drinks & $5.3 \pm 26.8$ & $0-183$ & $8.0 \pm 35.3$ & $0-183$ & $20.7 \pm 54.6$ & $0-365$ & 0.0001 & 0.003 & 0.01 & NS \\
\hline Sport drinks & $0.3 \pm 2.3$ & $0-17$ & 0 & 0 & $2.4 \pm 14.3$ & $0-104$ & NS & NS & NS & NS \\
\hline Apple vinegar & $0.4 \pm 2.0$ & $0-15$ & $0.9 \pm 4.3$ & $0-27$ & $0.6 \pm 4.7$ & $0-34$ & NS & NS & NS & NS \\
\hline Juice & $28.8 \pm 50.0$ & $0-230$ & $33.0 \pm 57.7$ & $0-230$ & $44.7 \pm 51.9$ & $0-183$ & 0.03 & NS & NS & NS \\
\hline Nutrition drinks & $25.3 \pm 55.7$ & $0-219$ & $15.5 \pm 50.5$ & $0-274$ & 0 & 0 & 0.0001 & 0.003 & 0.03 & NS \\
\hline Tea without sugar & $86.5 \pm 122.4$ & $0-438$ & $70.4 \pm 156.5$ & $0-949$ & $40.3 \pm 66.8$ & $0-237$ & NS & 0.04 & NS & NS \\
\hline Tea with sugar & $16.5 \pm 48.8$ & $0-256$ & $17.5 \pm 55.3$ & $0-329$ & $20.4 \pm 48.3$ & $0-219$ & NS & NS & NS & NS \\
\hline Coffee without sugar & $96.4 \pm 219.3$ & $0-1186$ & $88.3 \pm 224.9$ & $0-1186$ & $31.4 \pm 81.4$ & $0-329$ & NS & NS & NS & NS \\
\hline Coffee with sugar & $3.6 \pm 22.5$ & $0-164$ & $3.4 \pm 22.4$ & $0-164$ & $4.5 \pm 25.4$ & $0-183$ & NS & NS & NS & NS \\
\hline Milk & $89.7 \pm 94.3$ & $0-365$ & $69.5 \pm 101.6$ & $0-548$ & $107.1 \pm 107.9$ & $0-438$ & 0.001 & NS & 0.004 & 0.02 \\
\hline Water & $342.4 \pm 307.0$ & $0-1095$ & $386.1 \pm 463.7$ & $0-2008$ & $310.1 \pm 254.8$ & $0-1095$ & NS & NS & NS & NS \\
\hline Total drink intake (per above) & $758.2 \pm 452.7$ & $129-2444$ & $794.8 \pm 719.9$ & $0-3833$ & $623.9 \pm 286.7$ & $0-1462$ & NS & NS & NS & NS \\
\hline
\end{tabular}

$P$ refers to differences between the three groups by Friedman test. $P_{1}$ refers to difference between relatively good vs. control; $P_{2}$ bad vs. control; $P_{3}$ relatively good vs. bad (Wilcoxon Signed Rank Test)

vomiting group. No differences in nutrition drink intake were found in the vomiting group, while ED-good presented significantly higher intake $(32 \mathrm{~L})$ compared to controls $(0=\mathrm{L})(p=0.01)$ in the no vomiting group.

Grouping of the different types of drinks is shown in Table 2 and Friedman comparisons showed significant differences in intake of total soft drinks, carbonated soft drinks, regular soft drinks and caffeine-containing drinks (cola-type drink, tea and coffee). In pairwise comparisons using Bonferroni correction the controls reported significantly higher intake of carbonated regular soft drinks than both ED-good and bad groups (43.3 vs. 14.0 vs. 20.4; $p=0.0001$ and $p<0.001$ ). Yearly consumption of caffeine-containing drinks was significantly higher in ED-good than in controls (251.4 L vs. $125.8 \mathrm{~L} ; p=0.001$ ).
In the no vomiting group, total soft drink intake was significantly higher in the controls $(107 \mathrm{~L})$ compared to ED-good $(59.0 \mathrm{~L})(p=0.01)$. The same applied to carbonated regular soft drink intake in the no vomiting group where controls reported significantly higher intake $(52.6 \mathrm{~L})$ compared to ED-good $(18.2 \mathrm{~L})$ and bad $(17.6 \mathrm{~L})(p=0.002)$. In the vomiting group, controls reported significantly higher intake of total carbonated regular soft drinks $(32.5 \mathrm{~L})$ compared to ED-good $(9.1 \mathrm{~L}) \quad(p=0.01)$. Intake of caffeinecontaining drinks was higher in ED good compared to controls in the vomiting group $(330 \mathrm{~L}$ vs. $144 \mathrm{~L})$ $(p=0.009)$. No differences were found as regards caffeine drinks in the no vomiting subjects (see Additional file 2).

Table 2 Soft Drink Consumption (L/yr) in Relatively Good and Bad Disease State Compared to Healthy Controls

\begin{tabular}{|c|c|c|c|c|c|c|c|c|c|c|}
\hline & \multicolumn{2}{|l|}{$\begin{array}{l}\text { Relatively good } \\
(n=54)\end{array}$} & \multicolumn{2}{|l|}{$\begin{array}{l}\text { Bad } \\
(n=54)\end{array}$} & \multicolumn{2}{|l|}{$\begin{array}{l}\text { Control } \\
(n=54)\end{array}$} & \multirow[b]{2}{*}{ P } & \multirow[b]{2}{*}{$P_{1}$} & \multirow[b]{2}{*}{$P_{2}$} & \multirow[b]{2}{*}{$P_{3}$} \\
\hline & Mean \pm SD & Range & Mean \pm SD & Range & Mean \pm SD & Range & & & & \\
\hline Total soft drinks ${ }^{1}$ & $97.5 \pm 175.4$ & $0-1029$ & $135.8 \pm 292.8$ & $0-1752$ & $108.8 \pm 97.0$ & $0-511$ & 0.004 & NS & NS & NS \\
\hline Total carbonated soft drinks & $68.9 \pm 166.7$ & $0-1029$ & $103.4 \pm 277.7$ & $0-1752$ & $61.6 \pm 69.8$ & $0-365$ & 0.03 & NS & NS & NS \\
\hline Total carbonated light soft drinks & $54.9 \pm 162.9$ & $0-1029$ & $83.0 \pm 274.3$ & $0-1752$ & $18.3 \pm 43.4$ & $0-182$ & NS & NS & NS & NS \\
\hline Total carbonated regular soft drinks & $14.0 \pm 52.8$ & $0-313$ & $20.4 \pm 70.2$ & $0-365$ & $43.3 \pm 59.8$ & $0-365$ & 0.0001 & 0.0001 & 0.001 & NS \\
\hline Total caffeine-containing drinks ${ }^{2}$ & $251.4 \pm 254.6$ & $0-1186$ & $253.7 \pm 367.3$ & $0-1642$ & $125.8 \pm 123.2$ & $0-523.0$ & 0.047 & 0.001 & 0.047 & NS \\
\hline
\end{tabular}

$\mathrm{P}$ refers to differences between the three groups by Friedman test. $\mathrm{P}_{1}$ refers to difference between relatively good vs. control; $\mathrm{P}_{2}$ bad vs. control; $\mathrm{P}_{3}$ relatively good vs. bad (Wilcoxon Signed Rank Test)

${ }^{1}$ Carbonated beverages (light and regular), sport drinks, juice

${ }^{2}$ Cola-type drinks, tea, coffee 


\section{Food habits}

Number of meals was significantly different between the three groups at all types of reported occasions (Table 3). In pairwise tests, the ED-good group did not present any significant difference to the controls in any of the types of meal while the ED-bad group did so: weekly numbers of breakfast, lunch and dinner meals were all significant lower in the ED-bad group compared to controls $(p=$ 0.002 to $p=0.0001$ ). The same applied in comparisons between the two ED-groups.

In the vomiting group and compared to controls, EDbad had significantly lesser frequent intake of breakfast (3.9 vs. 6.0 times), lunch (3.7 vs. 6.6 times) and dinner (4.4 vs. 6.4) ( $p=0.008, p=0.001$ and $\mathrm{p}=0.001$, respectively). Comparisons between ED-good and bad showed that the latter had had significantly lesser intake than ED-good at all meal occasions except for in-between meals ( $p=0.016$ to $p=0.005)$. Both ED-good and bad in the no vomiting presented no differences compared to controls in number of meals/breakfast/lunch/dinner/in between meals. Comparison between ED-good and bad revealed that the latter had significantly lesser frequent intake of total meals/day (3.3 vs. 3.8 times) and lunch/ day (5.4 vs. 6.6 times) ( $p=0.002$ and $\mathrm{p}=0.005$, respectively) (see Additional file 2).

Regarding fruit consumption, the only significant difference detected was consumption of weekly intake of apples where the ED-good consumed more than controls (6.6 vs. 3.2; $p=0.006$ ) (Table 4). In the vomiting group and compared to the matched controls, no differences were found while in the no vomiting group EDbad consumed significantly more (6.9 apples/week) compared to controls (2.6 apples/week) $(p=0.01)$.

Sweets, sweet biscuits/buns and hard cheese were all significantly different in multiple comparisons between the three groups $(p=0.002$ to $p=0.0001)$ while the consumption of yoghurt/sour milk was not. In pairwise tests, both ED-good and bad groups reported significantly more often "never or seldom intake" of sweet biscuits/buns than the controls $(46.3 \%$ vs. $66.7 \%$ vs. $18.5 \%$; $p=0.004$ and $\mathrm{p}=0.0001)$. The ED-bad group had lesser frequent intake of sweets and 51.9\% reported intake "never or seldom" compared to controls of $16.7 \%$ ( $p=$ $0.001)$ and the same applied for hard cheese $(58.5 \%$ vs. $32.1 \%, p=0.003$ ) (Table 5).

In the vomiting group, no significant differences were found as regards intake of sweets, sweet biscuits/buns and yoghurt/sour milk but hard cheese was consumed more seldom in in the ED-bad group $(p=0.01)$. The controls in the no vomiting group consumed significantly more sweets/sweet biscuits, buns than the ED-bad $(p=0.002$ and $\mathrm{p}=0.001$, respectively) (see Additional file 2).

\section{Oral hygiene habits}

Number of daily tooth brushing differed significantly between the three groups $(p=0.016)$. In pairwise tests, none of the differences reached statistical significance $(p>0.017)$ and neither did length of tooth brushing or amount of tooth paste used (Table 6). Multiple comparisons of time related brushing showed statistical significances in morning, evening and after meal brushing ( $p=$ 0.039 to $p=0.004$ ) but in the pairwise tests only evening brushing turned out be statistically significant in that ED-bad reported less frequent brushing than controls ( $85 \%$ vs. $100 \%, p=0.008$ ) (data not shown). Responses relating proximal cleaning, rinsing and type of solution after brushing and use of saliva stimulating agents did not differ between ED groups and controls (data not shown).

In comparisons between the vomiting and no vomiting group, the only significant finding was that ED-good patients in the no vomiting group brushed their teeth more frequently than the controls $(2.4 \mathrm{vs}$. 2.0 times/day) $(p=0.015)$ (see Additional file 2).

\section{Awareness}

No differences between the groups regarding the perceived danger to the teeth of different food item (sour drinks and fruits), brushing after a dietary acidic challenge to the oral environment were found (data not shown). However, ED patients were significantly more aware of that vomiting may damage their teeth $(100 \%$ vs.

Table 3 Eating Habits in Relatively Good and Bad Disease State Compared to Healthy Controls

\begin{tabular}{|c|c|c|c|c|c|c|c|c|c|c|}
\hline & \multicolumn{2}{|c|}{$\begin{array}{l}\text { Relatively good } \\
(n=54)\end{array}$} & \multicolumn{2}{|l|}{$\begin{array}{l}\text { Bad } \\
(n=54)\end{array}$} & \multicolumn{2}{|l|}{$\begin{array}{l}\text { Control } \\
(n=54)\end{array}$} & \multirow[b]{2}{*}{$\mathrm{P}$} & \multirow[b]{2}{*}{$\mathrm{P}_{1}$} & \multirow[b]{2}{*}{$P_{2}$} & \multirow[b]{2}{*}{$P_{3}$} \\
\hline & Mean \pm SD & Range & Mean \pm SD & Range & Mean \pm SD & Range & & & & \\
\hline Number of meals/day & $3.8 \pm 1.5$ & $1-7$ & $3.0 \pm 1.8$ & $0-7$ & $3.4 \pm 1.0$ & $1-5.5$ & 0.002 & NS & NS & 0.001 \\
\hline Number breakfast/week & $6.0 \pm 2.1$ & $0-7$ & $4.8 \pm 2.9$ & $0-7$ & $6.3 \pm 1.5$ & $1-7$ & 0.0001 & NS & 0.0001 & 0.001 \\
\hline Number of lunch/week & $6.0 \pm 1.9$ & $0-7$ & $4.6 \pm 2.6$ & $0-7$ & $6.5 \pm 1.3$ & $1-7$ & 0.0001 & NS & 0.0001 & 0.0001 \\
\hline Number of dinner/week & $6.5 \pm 1.2$ & $2-7$ & $5.0 \pm 2.6$ & $0-7$ & $6.4 \pm 1.5$ & $1-7$ & 0.0001 & NS & 0.002 & 0.0001 \\
\hline Number of in-between meals/week & $6.3 \pm 3.5$ & $0-17$ & $4.9 \pm 6.1$ & $0-40$ & $5.1 \pm 3.0$ & $0-14$ & 0.02 & NS & NS & 0.02 \\
\hline
\end{tabular}

$P$ refers to differences between the three groups by Friedman test. $P_{1}$ refers to difference between relatively good vs. control; $P_{2}$ bad vs. control; $P_{3}$ relatively good vs. bad (Wilcoxon Signed Rank Test) 
Table 4 Fruit Intake (Number/Week) in Relatively Good and Bad Disease State Compared to Healthy Controls

\begin{tabular}{|c|c|c|c|c|c|c|c|c|c|c|}
\hline \multirow[b]{2}{*}{ No. of fruit intake/week } & \multicolumn{2}{|c|}{$\begin{array}{l}\text { Relatively good } \\
(n=54)\end{array}$} & \multicolumn{2}{|l|}{$\begin{array}{l}\text { Bad } \\
(n=54)\end{array}$} & \multicolumn{2}{|l|}{$\begin{array}{l}\text { Control } \\
(n=54)\end{array}$} & \multirow[b]{2}{*}{$P$} & \multirow[b]{2}{*}{$P_{1}$} & \multirow[b]{2}{*}{$\mathrm{P}_{2}$} & \multirow[b]{2}{*}{$P_{3}$} \\
\hline & Mean \pm SD & Range & Mean \pm SD & Range & Mean \pm SD & Range & & & & \\
\hline Apples & $6.6 \pm 8.6$ & $0-39$ & $6.6 \pm 13.0$ & $0-70$ & $3.2 \pm 4.7$ & $0-28$ & $0.07^{*}$ & 0.006 & NS & $\overline{N S}$ \\
\hline Pears & $2.3 \pm 4.2$ & $0-18$ & $2.9 \pm 8.0$ & $0-49$ & $0.9 \pm 1.7$ & $0-7$ & NS & NS & NS & NS \\
\hline Citrus fruits & $4.4 \pm 6.6$ & $0-28$ & $3.8 \pm 8.8$ & $0-53$ & $2.1 \pm 4.3$ & $0-21$ & NS & NS & NS & NS \\
\hline Bananas & $4.4 \pm 9.4$ & $0-64$ & $3.1 \pm 5.7$ & $0-28$ & $3.6 \pm 4.4$ & $0-25$ & 0.04 & NS & NS & NS \\
\hline
\end{tabular}

$P$ refers to differences between the three groups by Friedman test. $P_{1}$ refers to difference between relatively good vs. control; $P_{2}$ bad vs. control; $P_{3}$ relatively good vs. bad (Wilcoxon Signed Rank Test)

*Tendency for significance

$87 \%, p=0.008)$ and that tooth brushing after vomiting may create dental damage ( $71 \%$ vs. $35 \%, p=0.001)$.

\section{Utilization of dental care}

ED patients reported that they visit the dentist for ordinary recall significantly less often than controls $(78 \%$ vs. $93 \%, p=0.04)$. In the vomiting group only $68 \%$ reported regular dentist visits which were significantly lesser than the controls $(96 \%)(p=0.016)$ but no difference as regard ordinary recall dentist visit was found in the no vomiting group. Other questions related to emergency dental visits, dental fear and confidence in the dental care system and preference for a male or female dentist were not statistically different between ED patients and healthy controls and neither between the vomiting and no vomiting groups (data not shown).

\section{Physical exercise}

ED-bad reported an average of 3.6 times weekly exercise (range 0-20), ED-good 3.2 times/week (range 0-10) and the controls 2.8 times/week but differences were not statistically significant and neither between the vomiting and no vomiting groups.

\section{Conditional logistic regression}

The regression analyzes showed that the ED- good consumed significantly lesser regular carbonated soft drinks $(\mathrm{OR}=0.57)$ but more caffeine containing drinks $(\mathrm{OR}=$ 1.34) compared to controls. ED-bad had significantly lesser number of lunch meals and sweet biscuits intake per week (OR 0.59 and 0.15 , respectively). When comparing ED patients in relatively good and bad disease state the former had significantly more weekly intake of lunch $(\mathrm{OR}=1.73)$. Nagelkerke $\mathrm{R}^{2}$ for the three models ranged from 0.42 to 0.65 (Table 7).

\section{Discussion}

A common feature for ED patients is that the disease varies over the course of time with marked shifts in eating and other behaviors. In a more "active" state of the disease (presently termed "ED-bad") an AN patient is severely restricting the calorie intake in fear of gaining weight, and an $\mathrm{BN}$ patient has frequent periods of severe binge eating combined with different types of compensatory behavior (e.g. self-induced vomiting, fasting, extreme exercise or use of laxative/diuretics). EDNOS patients on the other hand, may engage in any of the abnormal eating or compensatory behaviors, while not fulfilling the criteria for an AN or BN diagnosis [17]. An ED patient may also have periods during which the sign and symptoms of the disease is relatively absent and she/he is feeling pretty good (presently termed "ED-good"). It was therefore deemed important to evaluate the ED patients both in a relatively good and a bad disease state as the two conditions might present different types of eating/dietary habits and behavior. In addition to the foregoing, purging behavior is common in ED patients and one such common behavior, namely vomiting or not, was therefore further analyzed in this study.

Table 5 Percentage Distribution of Intake of Dietary Items

\begin{tabular}{|c|c|c|c|c|c|c|c|c|c|c|}
\hline & \multicolumn{2}{|c|}{$\begin{array}{l}\text { Relatively good } \\
(n=54)\end{array}$} & \multicolumn{2}{|c|}{$\begin{array}{l}\text { Bad } \\
(n=54)\end{array}$} & \multicolumn{2}{|c|}{$\begin{array}{l}\text { Control } \\
(n=54) \\
\end{array}$} & \multirow[b]{2}{*}{$P$} & \multirow[b]{2}{*}{$P_{1}$} & \multirow[b]{2}{*}{$P_{2}$} & \multirow[b]{2}{*}{$P_{3}$} \\
\hline & 1 & 2 & 1 & 2 & 1 & 2 & & & & \\
\hline Sweets & 37.0 & 63.0 & 51.9 & 48.1 & 16.7 & 83.3 & 0.0001 & 0.03 & 0.001 & NS \\
\hline Sweet biscuits, buns & 46.3 & 53.7 & 66.7 & 33.3 & 18.5 & 81.5 & 0.0001 & 0.004 & 0.0001 & 0.04 \\
\hline Hard cheese & 51.9 & 48.1 & 58.5 & 41.5 & 32.1 & 67.9 & 0.002 & NS & 0.003 & NS \\
\hline Yoghurt/sour milk & 20.4 & 79.6 & 35.2 & 64.8 & 20.4 & 79.6 & NS & NS & NS & NS \\
\hline
\end{tabular}

$1=$ Never or seldom; 2 = One to several intake/month, week or day. $P$ refers to differences between the three groups by Friedman test. $P_{1}$ refers to difference between self-perceived relatively good vs. control; $P_{2}$ bad vs. control; $P_{3}$ relatively good vs. bad (McNemar's Test) 
Table 6 Oral Hygiene Habits in Relatively Good And Bad Disease State Compared to Healthy Controls

\begin{tabular}{|c|c|c|c|c|c|c|c|c|c|c|}
\hline & \multicolumn{2}{|c|}{$\begin{array}{l}\text { Relatively good } \\
(n=54)\end{array}$} & \multicolumn{2}{|l|}{$\begin{array}{l}\text { Bad } \\
(n=54)\end{array}$} & \multicolumn{2}{|l|}{$\begin{array}{l}\text { Control } \\
(n=54)\end{array}$} & \multirow[b]{2}{*}{$P$} & \multirow[b]{2}{*}{$P_{1}$} & \multirow[b]{2}{*}{$P_{2}$} & \multirow[b]{2}{*}{$P_{3}$} \\
\hline & Mean $\pm S D$ & Range & Mean \pm SD & Range & Mean $\pm S D$ & Range & & & & \\
\hline No. of brushing times/day & $2.3 \pm 0.7$ & $1-5.5$ & $2.6 \pm 1.5$ & $0-10$ & $2.1 \pm 0.5$ & $1-3.5$ & 0.016 & 0.026 & 0.018 & $\overline{N S}$ \\
\hline Toothbrushing min/time & $3.3 \pm 3.3$ & $1-22.5$ & $3.5 \pm 3.7$ & $0.5-22.5$ & $2.9 \pm 1.6$ & $1-7.5$ & NS & NS & NS & NS \\
\hline Cm tooth paste /brushing & $1.5 \pm 0.9$ & $0.3-6.5$ & $1.5 \pm 0.92$ & $0.3-6.5$ & $1.6 \pm 0.95$ & $0.2-5$ & NS & NS & NS & NS \\
\hline
\end{tabular}

$P$ refers to differences between the three groups by Friedman test. $P_{1}$ refers to difference between relatively good vs. control; $P_{2}$ bad vs. control; $P_{3}$ relatively good vs. bad (Wilcoxon Signed Rank Test)

There are a lack of well-controlled studies investigating the differences in eating habits between ED patients and healthy controls but gaining such information could be used for distinguishing patients from abnormal, but benign, eating behavior found in healthy subjects as well as phenotyping ED [18]. This study found that patients with ED has a higher intake of artificially sweetened beverages which is in agreement with previous findings [11, 13]. The preference for low-calorie dietary items is most likely connected to desire for ED patients not to gain weight in addition to that fluid intake suppress appetite $[13,19]$. As regards oral health, diet drinks does not cause dental caries but is a clear risk factor for dental erosion which is a common finding in ED patients [1]. The vomiting group had a significantly higher intake of cola type light drinks which in combination with their purging behavior may substantially increase the risk for dental erosion and previous reports have found this to be true $[1,20]$.

Intake of caffeine-containing drinks was about double in the two ED groups compared to controls, a finding

Table 7 Conditional logistic regression. Final model, stepwise forward entry method

\begin{tabular}{|c|c|c|c|}
\hline & $P$ & OR & $95 \% \mathrm{Cl}$ for $\mathrm{OR}$ \\
\hline \multicolumn{4}{|c|}{ Model A: ED relatively good vs. controls (ref category: ED-good) } \\
\hline Regular soft drinks & 0.03 & 0.57 & $0.35-0.94$ \\
\hline Caffeine-containing drinks & 0.005 & 1.34 & $1.10-1.64$ \\
\hline \multicolumn{4}{|c|}{ Model B: ED-bad disease state vs. controls (ref category: ED-bad) } \\
\hline Lunch & 0.01 & 0.59 & $0.39-0.88$ \\
\hline Sweet biscuits & 0.001 & 0.15 & $0.05-0.48$ \\
\hline \multicolumn{4}{|c|}{ Model C: ED-good vs. bad (ref category: ED-good) } \\
\hline Lunch & 0.03 & 1.73 & $1.05-2.89$ \\
\hline
\end{tabular}

Included independent variables:

Model A: relatively good disease state vs. controls. Included independent variables - Consumption of Cola light, Cola regular, total carbonated regular soft drinks, total caffeine-containing drinks (L/week), apples (no/week), sweet biscuits (never/seldom or > one intake per month)

Model B: bad disease state vs. controls. Included independent variables - Cola regular, total carbonated regular soft drinks, milk (L/week), lunch (no/week), sweet biscuits, hard cheese (never/seldom or > one intake per month) Model C: relatively good vs. bad disease state. Included independent variables - Nutrition drinks (L/week), breakfast, lunch, dinner, in-between meals (no/ week), sweet biscuits (never/seldom or > one intake per month) Model A: Nagelkerke $R^{2}=0.42$. Model B: Nagelkerke $R^{2}=0.65$. Model C: Nagelkerke $R^{2}=0.45$ that contrast another study reporting an average intake in ED patients similar to that of the general population [21]. However, it has also been found that young girls with AN show a higher caffeine intake compared to controls which a least in part support the findings in this study [22]. Nevertheless, caffeine may suppress appetite [23] and it has been suggested that caffeine is used by ED patients to control weight and shape which is especially true for those who engage in purging or binge eating behavior [18]. There is no direct relationship between caffeine and oral health but many of the available soft drinks commonly consumed by ED patients contain caffeine and these drinks may have adverse oral consequences depending on their content of acidic/sugary constituents. The most obvious finding as regards caffeine containing drinks was in the vomiting group (ED-good) reported more than double the amount of intake caffeine compared to controls.

Meal skipping is common in ED patients and has previously been reported on [24, 25]. In this study, number of daily or weekly meals did not differ significantly between ED-good condition and controls. ED-bad on the other hand, had significantly lesser weekly intake of both breakfast, lunch and dinner compared to controls. This finding was exclusively found in the vomiting ED-bad group who skipped breakfast, lunch and dinner significantly more often than controls but no such difference was found in no vomiting patients. Within the ED group number of meals per day were reduced in bad compared to relatively good disease state. Skipping meals may have a negative effective, both on oral health [26] and a number of conditions related general health [27]. This finding highlights the importance of getting reports from ED patients not only in general terms but specifically about behavior when they are in a more active disease stage, i.e. ED-bad in this study.

Not unsurprisingly, intake of sweets and sweet biscuits were significantly lower in ED patients compared to controls and was especially pronounced during ED-bad condition. This finding was especially pronounced in the no vomiting while no differences were found in the vomiting group. One could argue therefore that the controls should have a higher risk for dental caries depending on a higher intake of sugary items. However, the no 
vomiting group comprised to great extent of anorectic patients (AN) or combinations thereof (EDNOS) and this group is especially vulnerable to oral diseases depending on their bad physical state including impaired salivary secretion and altered biochemical saliva composition [15].

The regression analyzes was performed with a selection of dietary items as independent variables and the final model predicted ED-good patients compared to controls on lower intake of regular soft drinks and higher intake of caffeine containing drinks. The corresponding prediction of ED-bad was lower number on lunch meals and intake of sweet biscuits. When comparing the ED-bad and good groups, the former had more frequent lunch and dinner meals and higher intake of nutrition drinks (drinks high in nutrition and energy, often recommended/prescribed to patients in special need having difficulties to eat). The results corroborate the above discussion and highlights the importance of penetrating the dietary history when examining ED patients and again the importance of getting report from their behavior in both good and bad disease state.

A common clinical impression is that ED patients more intensely and more often brush their teeth than healthy individuals. Number of brushing times per day were significantly higher among ED than in controls and more marked during ED-bad condition and especially so in the no vomiting group. These findings agree with a recently published study where more frequent toothbrushing were observed in patients with eating disorders compared to controls [28]. One study showed $32.5 \%$ of participants reported that BN patients brushed their teeth immediately after purging, [29] and another report found that tooth brushing after vomiting in ED patients had a detrimental effect on dental erosion [20]. Consequently, tooth brushing frequency should be recorded in ED patients and its tentative negative effect in relation to acidic challenges such as vomiting or soft drink intake should be informed about.

As regards awareness of dietary intake and the possible risk for oral health complications did not differ between patients and controls except that the ED groups were more aware that vomiting and brushing thereafter could damage their teeth, a finding which is positive. On the other hand, ED went less often to the dentist for regular checkups than controls which is a negative finding and patients with ED therefore needs to be encouraged to attend dental checkups more frequent since they have an increased risk for oral problems/diseases [6, 30-37]. This is deemed to be especially important for vomiting ED patients where only $68 \%$ reported regular dentist visits. Opposite finding was reported in another study where ED patients visited the dentist at least once a year, more often than controls ( $75 \%$ vs. $51.4 \%$ ) [28]. The higher attendance of regular visits among the controls in this study (>90\%) may be explained by the well-organized Swedish public dental health system for children and adolescents which since decades back offers dental care (yearly routine checkups /emergency visits) free of charge.

The strength of the present study is that the ED group was drawn from a consecutive series of patients seeking treatment, which numbered to 65 participants during a one-year period. The relatively high participation rate of $83 \%(54 / 65)$ may lead to the conclusion that the results are fairly representative for ED patients seeking outpatient rehabilitation. Certain weaknesses of the study can be mentioned. The sample was small and the "risk for random occurrences" is therefore higher. The ED group was selected from an outpatient ED clinic and the results from this study may not be completely transferable to inpatients. The questionnaire was not validated according to standard procedures. However, in the construction of the questionnaire it was considered that the ED patients in many aspects present large variations not only in age and diagnoses but also regarding symptoms, expressivity, duration of their disease. The construction of the questionnaire was therefore based on available research reports in combination with the clinical experience from the multiprofessional team working with this group of patients. The division of the patients into ED-good and bad was based upon the patient's subjective opinion which is difficult to transfer an objective assessment of the real disease state. In the vomiting/no vomiting groups the response was based on a single question ("Are you presently or previously been engaged in self-induced vomiting") and does not give any detailed information about for example frequency, timing etc. of the behavior. Such information would have been valuable to retrieve in order to more accurately analyze its consequences.

\section{Conclusions}

The conclusions drawn from this study are that ED patients presents a number of dietary and other types of behavior that are potentially harmful for their general and oral health. For a more accurate detection of these activities, it is important that the patient report on the behaviors both when she/he is in a relatively good as well as being in a more active disease state. This could help the medical team to prescribe more adequate advice and treatment. The hypothesis that diet and other behavioral habits differ among ED patients depending on their disease state was supported.

\section{Supplementary information}

Supplementary information accompanies this paper at https://doi.org/10. 1186/s40337-020-0281-z.

Additional file 1. Questionnaires for the ED and Control Groups (in Swedish). 
Additional file 2: Table S1. Drink Intake, Eating and Oral Hygiene Habits in Relatively Good and Bad Disease State Compared to Healthy Controls in vomiting and no vomiting patients ${ }^{1}$ compared to healthy controls. Table S2. Percentage Distribution of Intake of Dietary Items in Relatively Good and Bad Disease State in vomiting and no vomiting patients ${ }^{1}$ Compared to Healthy Controls.

\section{Abbreviations}

AN: Anorexia nervosa; BN: Bulimia nervosa; ED: Eating disorder; ED-bad: selfperceived ED status reported as "bad"; ED-good: self-perceived ED status reported as "relatively good"; EDI-2: Symptom index of the eating disorder inventory-2; EDNOS: Eating disorder not otherwise specified

\section{Acknowledgements}

This study was supported by grants Örebro County Council, Örebro, Sweden. We would like to express our thanks to the personnel at the Eating Disorder Clinic, Eriksbergsgården, and Mrs. Kristina Ekman for invaluable assistance, Örebro County Council, Örebro, Sweden. The authors gratefully acknowledge Stein Atle Lie, Biostatistician, Department of Clinical Dentistry, University of Bergen for his support in the statistical analyzes.

\section{Authors' contributions}

AKJ: Study design, statistical analyses, scientific writing of the manuscript. CN: Study design, statistical analyses, scientific writing of the manuscript. LU: Statistical analyses, scientific writing of the manuscript. AJ: Study design, statistical analyses, scientific writing of the manuscript. All authors read and approved the final manuscript.

\section{Funding}

This study was supported by grants Örebro County Council, Örebro.

\section{Availability of data and materials}

The dataset used and/or analyzed during the current study are available from the corresponding author on reasonable request.

\section{Ethics approval and consent to participate}

The study was approved by the Ethics Committee in the Örebro region, Sweden (No: 298/03) and informed consent was obtained from all participants. In cases of children, parental consent was also obtained. As an incentive for participation in the study, all control subjects were offered cinema tickets (children) and/or a routine recall free of charge (adults).

\section{Consent for publication}

Not applicable.

\section{Competing interests}

The authors report no conflicts of interests in relation to this paper.

\section{Author details}

${ }^{1}$ Department of Clinical Dentistry-Cariology, Faculty of Medicine, University of Bergen, Årstadveien 19, 5009 Bergen, Norway. ${ }^{2}$ Department of Clinical Neuroscience, Karolinska Institutet, Stockholm, Sweden. ${ }^{3}$ School of Health and Medical Sciences, Örebro University and Region Örebro County Council, Örebro, Sweden. ${ }^{4}$ Department of Clinical Dentistry-Prosthodontics, Faculty of Medicine, University of Bergen, Bergen, Norway.

Received: 27 August 2019 Accepted: 30 January 2020

Published online: 27 February 2020

\section{References}

1. Johansson AK, Norring C, Unell L, Johansson A. Eating disorders and oral health: a matched case-control study. Eur J Oral Sci. 2012;120:61-6.

2. Johansson AK, Johansson A, Unell L, Norring C, Carlsson GE. Eating disorders and signs and symptoms of temporomandibular disorders: a matched casecontrol study. Swed Dent J. 2010;34:139-47.

3. Kisely S, Baghaie H, Lalloo R, Johnson NW. Association between poor oral health and eating disorders: systematic review and meta-analysis. $\mathrm{Br} J$ Psychiatry. 2015;207:299-305.
4. Arcelus J, Mitchell AJ, Wales J, Nielsen S. Mortality rates in patients with anorexia nervosa and other eating disorders. A meta-analysis of 36 studies. Arch Gen Psychiatry. 2011;68:724-31.

5. Keel PK, Brown TA. Update on course and outcome in eating disorders. Int Eat Disord. 2010;43:195-204.

6. Lo Russo L, Campisi G, Di Fede O, Di Liberto C, Panzarella V, Lo ML. Oral manifestations of eating disorders: a critical review. Oral Dis. 2008;14:479-84

7. Uhlen MM, Tveit AB, Stenhagen KR, Mulic A. Self-induced vomiting and dental erosion--a clinical study. BMC Oral Health. 2014;14:92.

8. Hermont AP, Pordeus IA, Paiva SM, Abreu MH, Auad SM. Eating disorder risk behavior and dental implications among adolescents. Int J Eat Disord. 2013; 46:677-83.

9. Emodi-Perlman A, Yoffe T, Rosenberg N, Eli I, Alter Z, Winocur E. Prevalence of psychologic, dental, and temporomandibular signs and symptoms among chronic eating disorders patients: a comparative control study. J Orofac Pain. 2008;22:201-8

10. Hasselkvist A, Johansson A, Johansson AK. Association between soft drink consumption, oral health and some lifestyle factors in Swedish adolescents. Acta Odontol Scand. 2014;72:1039-46.

11. Klein DA, Boudreau GS, Devlin MJ, Walsh BT. Artificial sweetener use among individuals with eating disorders. Int J Eat Disord. 2006;39:341-5.

12. Schebendach JE, Mayer LE, Devlin MJ, Attia E, Contento IR, Wolf RL, Walsh BT. Dietary energy density and diet variety as predictors of outcome in anorexia nervosa. Am J Clin Nutr. 2008;87:810-6. Erratum in: Am J Clin Nutr. 2012;96: 222.

13. Brown TA, Keel PK. What contributes to excessive diet soda intake in eating disorders: appetitive drive, weight concerns, or both? Eat Disord. 2013;21: 265-74.

14. Nevonen L, Clinton D, Norring C. Validating the EDI-2 in three Swedish female samples: eating disorders patients, psychiatric outpatients and normal controls. Nord J Psychiatry. 2006;60:44-50.

15. Johansson AK, Norring C, Unell L, Johansson A. Eating disorders and biochemical composition of saliva: a retrospective matched case-control study. Eur J Oral Sci. 2015:123:158-64.

16. American Psychiatric Association. Diagnostic and Statistical Manual of Mental Disorders, 4th edition (DSM-IV). Washington, DC, APA, 1994.

17. Wierenga CE, Ely A, Bischoff-Grethe A, Bailer UF, Simmons AN, Kaye WH. Are extremes of consumption in eating disorders related to an altered balance between reward and inhibition? Front Behav Neurosci. 2014;8:410.

18. Forbush KT, Hunt TK. Characterization of eating patterns among individuals with eating disorders: what is the state of the plate? Physiol Behav. 2014; 134:92-109.

19. Hart S, Abraham S, Franklin RC, Russell J. The reasons why eating disorder patients drink. Eur Eat Disord Rev. 2011;19:121-8.

20. Otsu M, Hamura A, Ishikawa Y, Karibe H, Ichijyo T, Yoshinaga Y. Factors affecting the dental erosion severity of patients with eating disorders. Biopsychosoc Med. 2014;8:25. https://doi.org/10.1186/1751-0759-8-25.

21. Burgalassi A, Ramacciotti CE, Bianchi M, Coli E, Polese L, Bondi E, Massimetti G, Dell'osso L. Caffeine consumption among eating disorder patients: epidemiology, motivations, and potential of abuse. Eat Weight Disord. 2009; 14:e212-8.

22. Striegel-Moore RH, Franko DL, Thompson D, Barton B, Schreiber GB, Daniels SR. Caffeine intake in eating disorders. Int J Eat Disord. 2006:39:162-5.

23. Jessen A, Buemann B, Toubro S, Skovgaard IM, Astrup A. The appetitesuppressant effect of nicotine is enhanced by caffeine. Diabetes Obes Metab. 2005;7:327-33.

24. Masheb RM, Grilo CM, White MA. An examination of eating patterns in community women with bulimia nervosa and binge eating disorder. Int J Eat Disord. 2011:44:618-24.

25. Lavender JM, Utzinger LM, Crosby RD, Goldschmidt AB, Ellison J, Wonderlich SA, Engel SG, Mitchell JE, Crow SJ, Peterson CB, Le Grange D. A naturalistic examination of the temporal patterns of affect and eating disorder behaviors in anorexia nervosa. Int J Eat Disord. 2016:49:77-83.

26. Vierola A, Suominen AL, Eloranta AM, Lintu N, Ikävalko T, Närhi M, Lakka TA. Determinants for craniofacial pains in children 6-8 years of age: the PANIC study. Acta Odontol Scand. 2017;75:453-60.

27. St-Onge MP, Ard J, Baskin ML, Chiuve SE, Johnson HM, Kris-Etherton P, Varady K; American Heart Association Obesity Committee of the Council on Lifestyle and Cardiometabolic Health; Council on Cardiovascular Disease in the Young; Council on Clinical Cardiology; and Stroke Council. Meal timing and frequency: Implications for cardiovascular disease prevention: A 
scientific statement from the American Heart Association. Circulation. 2017 28;135:e96-e121.

28. Pallier A, Karimova A, Boillot A, Colon P, Ringuenet D, Bouchard P, Rangé H. Dental and periodontal health in adults with eating disorders: a casecontrol study. J Dent. 2019;84:55-9.

29. Conviser JH, Fisher SD, Mitchell KB. Oral care behavior after purging in a sample of women with bulimia nervosa. Am Dent Assoc. 2014;145:352-4.

30. Hermont AP, Oliveira PA, Martins CC, Paiva SM, Pordeus IA, Auad SM. Tooth erosion and eating disorders: a systematic review and meta-analysis. PLoS One. 2014;9:e11112.

31. Schlueter N, Ganss C, Pötschke S, Klimek J, Hannig C. Enzyme activities in the oral fluids of patients suffering from bulimia: a controlled clinical trial. Caries Res. 2012;46:130-9.

32. Öhrn R, Enzell K, Angmar-Månsson B. Oral status of 81 subjects with eating disorders. Eur J Oral Sci. 1999:107:157-63.

33. Hellström I. Oral complications in anorexia nervosa. Scand J Dent Res. 1977; 85:71-86.

34. Öhrn R, Angmar-Månsson B. Oral status of 35 subjects with eating disorders--a 1-year study. Eur J Oral Sci. 2000;108:275-80.

35. Rytömaa I, Järvinen V, Kanerva R, Heinonen OP. Bulimia and tooth erosion. Acta Odontol Scand. 1998;56:36-40.

36. Ximenes R, Couto G, Sougey E. Eating disorders in adolescents and their repercussions in oral health. Int J Eat Disord. 2010;43:59-64.

37. Dynesen AW, Bardow A, Petersson B, Nielsen LR, Nauntofte B. Salivary changes and dental erosion in bulimia nervosa. Oral Surg Oral Med Oral Pathol Oral Radiol Endod. 2008;106:696-707.

\section{Publisher's Note}

Springer Nature remains neutral with regard to jurisdictional claims in published maps and institutional affiliations.

Ready to submit your research? Choose BMC and benefit from:

- fast, convenient online submission

- thorough peer review by experienced researchers in your field

- rapid publication on acceptance

- support for research data, including large and complex data types

- gold Open Access which fosters wider collaboration and increased citations

- maximum visibility for your research: over $100 \mathrm{M}$ website views per year

At $\mathrm{BMC}$, research is always in progress.

Learn more biomedcentral.com/submissions 